\title{
Subsurface flow and large-scale lateral saturated soil hydraulic conductivity in a Mediterranean hillslope with contrasting land uses
}

\author{
Mario Pirastru ${ }^{1 *}$, Vincenzo Bagarello², Massimo Iovino ${ }^{2}$, Roberto Marrosu ${ }^{1}$, Mirko Castellini ${ }^{3}$, \\ Filippo Giadrossich ${ }^{1}$, Marcello Niedda $^{1}$ \\ ${ }^{1}$ Dipartimento di Agraria, Università degli Studi di Sassari, Viale Italia 39, 07100, Sassari, Italy. \\ ${ }^{2}$ Dipartimento di Scienze Agrarie e Forestali, Università degli Studi di Palermo, Viale delle Scienze, 90128, Palermo, Italy. \\ ${ }^{3}$ Consiglio per la ricerca in agricoltura e l'analisi dell'economia agraria - Unita di ricerca per i sistemi colturali degli ambienti caldo-aridi \\ (CREA-SCA), Via Celso Ulpiani 5, 70125, Bari, Italy. \\ * Corresponding author. Tel.: +39 079229342. E-mail: mpirastru@uniss.it
}

\begin{abstract}
The lateral saturated hydraulic conductivity, $K_{s, l}$, is the soil property that mostly governs subsurface flow in hillslopes. Determinations of $K_{s, l}$ at the hillslope scale are expected to yield valuable information for interpreting and modeling hydrological processes since soil heterogeneities are functionally averaged in this case. However, these data are rare since the experiments are quite difficult and costly. In this investigation, that was carried out in Sardinia (Italy), large-scale determinations of $K_{s, l}$ were done in two adjacent hillslopes covered by a Mediterranean maquis and grass, respectively, with the following objectives: i) to evaluate the effect of land use change on $K_{s, l}$, and ii) to compare estimates of $K_{s, l}$ obtained under natural and artificial rainfall conditions. Higher $K_{s, l}$ values were obtained under the maquis than in the grassed soil since the soil macropore network was better connected in the maquis soil. The lateral conductivity increased sharply close to the soil surface. The sharp increase of $K_{s, l}$ started at a larger depth for the maquis soil than the grassed one. The $K_{s, l}$ values estimated during artificial rainfall experiments agreed with those obtained during the natural rainfall periods. For the grassed site, it was possible to detect a stabilization of $K_{s, l}$ in the upper soil layer, suggesting that flow transport capacity of the soil pore system did not increase indefinitely. This study highlighted the importance of the experimental determination of $K_{s, l}$ at the hillslope scale for subsurface modeling, and also as a benchmark for developing appropriate sampling methodologies based on near-point estimation of $K_{s, l}$.
\end{abstract}

Keywords: Subsurface runoff; Drain; Pore connectivity; Sprinkling experiments; Land use change; Maquis.

\section{INTRODUCTION}

Lateral saturated subsurface flow is the dominating runoff generation mechanism in most hillslopes or catchments of the humid temperate climates (Weiler et al., 2005) but it also occurs in many semiarid regions (Newman et al., 1998; Niedda and Pirastru, 2013; Van Schaik et al., 2008).

The most suitable approach for studying the mechanisms that govern the subsurface response of vegetated hillslopes consists of excavating open trenches or installing drains to intercept and measure directly the saturated subsurface flow moving above an impeding layer. The reason is that the measured outflow integrates the heterogeneous hydrological response of the soil in the hillslope, which can be governed by flow through the spatially and temporally variable soil macropores (Beven and Germann, 2013; Chappel, 2010). The primary role of the macropores in determining timing, peak and volume of the generated subsurface flow has been demonstrated in different large-scale investigations, that were primarily carried out in humid or temperate climates (Anderson et al., 2009; Dusek et al., 2012; Jost et al., 2012; Uchida et al., 2004). For example, Anderson et al. (2009) found that the hydraulic connectivity of the preferential flow network at the hillslope scale was an important factor governing subsurface flow, and they were able to determine relationships between lateral flow, hillslope length and various storm indicators. Uchida et al. (2004) found that hillslope discharge during storms was mainly due to macropore flow, which was strongly related to the crosssectional area of the upslope saturated layer.

In semi-arid regions, subsurface processes have traditionally been considered less important than surface flow for discharge production. However, models which explicitly simulate lateral saturated subsurface flow in hillslopes (Maneta et al., 2008; Niedda and Pirastru, 2015; Van Schaik et al., 2014) suggest that subsurface flow plays a key role on catchment-scale hydrology even in semi-arid regions. In any case, little information is still available about the dominant mechanism of subsurface flow generation in many semiarid environments, including the Mediterranean ones. For these regions, there is the need to sample subsurface flow in natural hillslopes and to establish sources of spatial and temporal variability.

The lateral saturated hydraulic conductivity, $K_{s, l}$, is the soil property that mostly governs lateral water transport in hillslopes and it is a key parameter in many numerical models that simulate hydrological processes both at the hillslope (Dusek and Vogel, 2016; Hillbert et al., 2005) and catchment (Maneta et al., 2008; Matonse and Kroll, 2013; Niedda et al., 2014) scales. For example, $K_{s, l}$ has to be known to estimate soil erosion with the modified Morgan-Morgan-Finney model by Morgan and Duzant (2008). The $K_{s, l}$ data used for modeling purposes should be determined in agreement with the considered flow direction. In fact, anisotropy can determine saturated conductivity differing, even greatly (four orders of magnitude or more), with the considered direction (e.g., Bathke and Cassel, 1991; Beckwith et al., 2003; Bouma and Dekker, 1981; Dabney and Selim, 1987). This circumstance is relevant for interpreting soil hydrological processes (Montgomery and Dietrich, 1995).

A variety of approaches can be found in the literature to determine $K_{s, l}$. For example, approximate criteria, based on soil textural characteristics alone (e.g. $K_{s, l}=2100 \mathrm{~mm} \mathrm{~h}^{-1}$ for a sandy loam soil according to Morgan and Duzant (2008)), can be used. However, these values should be used with caution, 
being unverified. Various experimental techniques have been applied for small-scale estimates of $K_{s, l}$. These techniques include constant- and falling-head borehole permeameter techniques specifically developed for radial flow (Reynolds, 2010, 2011) and measurements on soil monoliths (Baxter et al., 2003; Blanco-Canqui et al., 2002; Chappell and Lancaster, 2007). Other methodologies have been developed with the specific objective to sample large to very large (dozens of $\mathrm{m}^{2}$ ) areas, but only a few investigations of such a type can be found in the literature (Brooks et al., 2004; Chappell and Lancaster, 2007; Montgomery and Dietrich, 1995). The $K_{s, l}$ determinations obtained with large-scale experiments can be expected to allow an improved representation of heterogeneity effects on the hillslope hydrological response as compared with near-point measurements. The scarcity of large-scale investigations is due to the fact that the experiments are expensive and difficult to conduct. Brooks et al. (2004) determined the hillslope-scale $K_{s, l}$ as a function of the water table depth below the soil surface using drainage measurements performed on a $18 \mathrm{~m}$ wide isolated sloped land. These authors found that $K_{s, l}$ increased abruptly near the surface, due to the activation of flow in the nearsurface macropores of biological origin. The reported hillslopescale estimation of $K_{s, l}$ was 3.2-13.7 times greater than the available small-scale measurements. Montgomery and Dietrich (1995) estimated the large scale $K_{s, l}$ based on the discharge from a gully cut which showed evidence of macropore flow. Their determinations were comparable with the greatest conductivity obtained by falling-head tests in piezometers. Chappell and Lancaster (2007) applied six field methods (i.e., slug test, constant- and falling-head borehole permeameter, ring permeameter, as well as two types of trench tests) to determine $K_{s, l}$. The large-scale $K_{s, l}$ values determined by the trench percolation tests were, on average, 37 times larger than the mean conductivity obtained by slug tests made in piezometers adjacent to the trenches.

Greater values of $K_{s, l}$, even by several orders of magnitude as compared with those determined at the point-scale, can be found when hydrological models are calibrated using the observed hydrologic response of the catchment (Blain and Milly, 1991; Chappell et al., 1998; Grayson et al., 1992). These discrepancies were generally attributed to the large-scale effects of macropore flow. However, Sherlock et al. (2000) also suggested that the differences between the measured and calibrated hydraulic conductivities could be linked to offsetting effects of the conceptual simplifications of the applied hydrological model, as well as to error effects of the other parameters involved.

In summary, our experimental knowledge of lateral subsurface flow processes in semi-arid environments is still incomplete notwithstanding that there are signs that these processes can be relevant even in these environments. Large-scale experiments are rare in general although they represent an efficient way to obtain directional soil hydraulic properties functionally averaging local heterogeneities.

This study focuses on the lateral subsurface flow processes in a hillslope with a different vegetation cover in the semiarid Mediterranean climate. A continuous monitoring of the lateral saturated subsurface flow and of the water table levels was carried out for two years in two contiguous areas, one covered with natural maquis and the other covered with grass established after the maquis clearing. The specific objective was to determine the subsurface flow response and the lateral saturated soil hydraulic conductivity of the two sampled hillslopes under both natural and artificial rainfall.

\section{MATERIALS AND METHODS Site description}

The study was performed in the Baratz Lake catchment (Giadrossich et al., 2015; Niedda et al., 2014; Pirastru and Niedda, 2013), in North-West Sardinia, Italy. The climate is semiarid Mediterranean, with a mild winter, a warm summer and a high water deficit between April and September. The mean annual temperature is $15.8^{\circ} \mathrm{C}$ and the mean relative humidity is $78.7 \%$. The minimum and maximum mean daily temperatures are $3^{\circ} \mathrm{C}$ and $29^{\circ} \mathrm{C}$, respectively. The average annual precipitation is about $600 \mathrm{~mm}$, and this falls almost all from autumn to spring. The potential evapotranspiration is around $1000 \mathrm{~mm} \mathrm{year}^{-1}$.

The experimental area was on the steep side of a hill (Figure 1). It has a mean elevation of $63 \mathrm{~m}$ a.s.l. and it is about $60 \mathrm{~m}$ long. The sloped surface is roughly planar, faces north and has a mean gradient of $30 \%$. In the upper part, the incoming overland and subsurface flows are diverted by the ditches alongside a road. At the foot, the hillslope is drained by the incised stream of the main river of the catchment area.

Two adjacent sites in the hillslope were selected for the research. One site is covered with a well-developed Mediterranean maquis (hereafter named HM site). It consists of a very dense growth of evergreen trees and shrubs with a height of

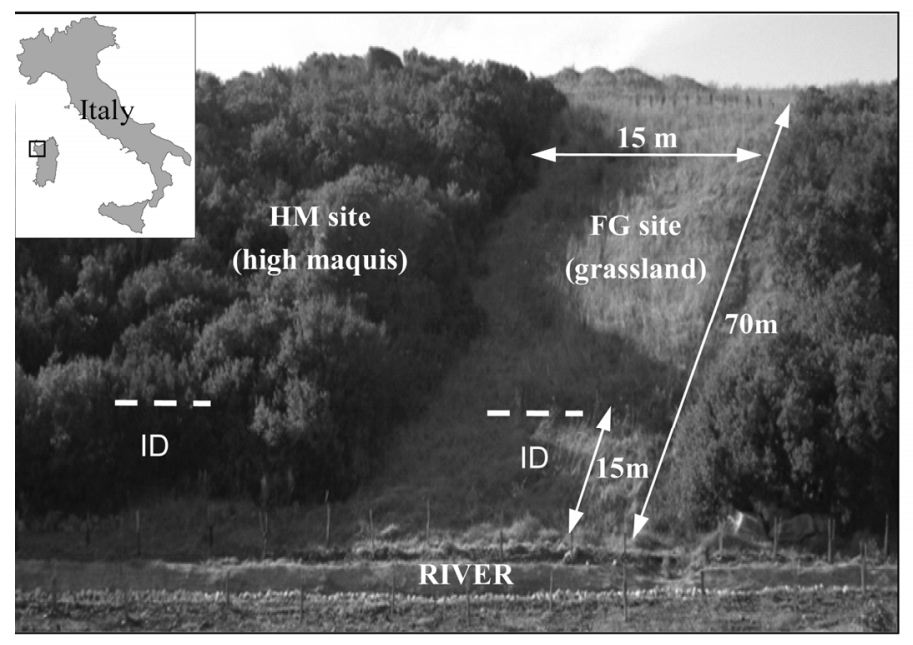

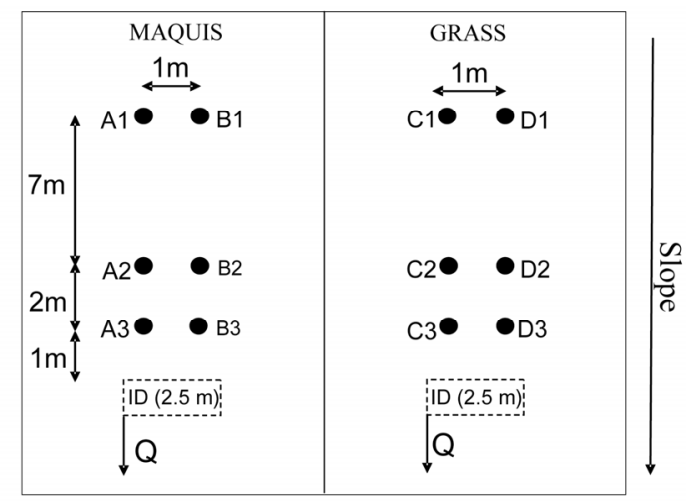

- Wells with TDR probes Interceptor drain (ID)

Fig. 1. View of the experimental hillslope, with location of the interceptor drains (ID) and spatial disposition of the piezometers at the FG and $\mathrm{HM}$ sites. The setup is not to scale. 
2-4 m composed by Myrtus Communis L., Arbutus unedo L., Erica arborea L., Phillirea latifolia L. and Pistacia lentiscus L. A litter at least $10 \mathrm{~cm}$ thick overlies the mineral soil at this site.

The other site is an unmanaged area covered with spontaneous grass (hereafter named FG site). This area developed about 15 years ago, after maquis clearing and mouldboard ploughing to create a $15 \mathrm{~m}$ wide firebreak.

The soil in the hillslope is Lithic Haploxerepts. It is about $0.4-0.5 \mathrm{~m}$ deep and overlies a grayish, altered substratum of Permian sandstone, which is very dense. This impeding layer limits deep water percolation. The soil texture is sandy-loam according to the USDA standards.

Field observations at the sites indicate that macropores due to grass or tree roots and animal burrows are mainly present near the surface. Detailed information about the hydraulic characteristics of the soils in the HM and FG sites are reported in Castellini et al. (2016) and Pirastru et al. (2014).

\section{Measurement of lateral subsurface flow}

Continuous hydro-meteorological data were collected at the experimental site from January 2014 to December 2015. The gross rainfall was measured every 5 minutes by a tipping bucket rain gauge $(0.2 \mathrm{~mm}$ of resolution) in an automatic weather station $500 \mathrm{~m}$ away from the studied hillslope. The lateral saturated subsurface flow above the impeding layer was collected by two $2.5 \mathrm{~m}$ long French drains that were installed $15 \mathrm{~m}$ from the slope foot, as shown in Figure 1. At the FG site, the drain was installed centrally to the grassed area, and at the HM site it was about $10 \mathrm{~m}$ far from the lateral maquis border. Outflow from each drain was routed in a plastic box which outlet is a $60^{\circ} \mathrm{V}$-notch weir. The water head over the V-notch was measured by a stand-alone pressure transducer every 5 minutes, and related with the flow rate by the weir formula. The outgoing flow from the box dropped into an automated tipping bucket (about $2 \cdot 10^{-3} \mathrm{~L} /$ tip), thus providing a more accurate measure of the flow rate when this was smaller than $0.4 \mathrm{~L} \mathrm{~min}^{-1}$.

Twelve piezometers were hand-drilled until the impeding layer was reached (Figure 1). On each hillslope, six wells were grouped in two adjacent transects positioned upslope and perpendicular to the drain. Within a transect, three wells were spaced at a distance of 1,3 and $10 \mathrm{~m}$ from the drain. As a convention, the transects were denoted by the letters from $A$ to $D$ and the wells in each transect were progressively numbered from the top to the bottom (Figure 1). Each well had a diameter of $80 \mathrm{~mm}$ and it was screened by $0.3 \mathrm{~m}$ above the top of the impeding layer. The depth of the soil, as documented when drilling the wells, ranged from 0.35 to $0.45 \mathrm{~m}$ at the FG site, and from 0.38 to $0.44 \mathrm{~m}$ at the HM site. The wells were equipped with automated TDR probes (Campbell Scientific Inc. CS216 Water Content Reflectometers, two-rod model, $0.3 \mathrm{~m}$ rod-length and $32 \mathrm{~mm}$ spacing), standing vertically in the wells, whose output was recorded every 5 minutes. As the probe rods were short compared to the soil thickness, they were periodically moved up or down in the wells to maintain them always partially submerged. The relationship between the TDR output and the percentage of rod submergence was calibrated in the laboratory. This relationship, with the reference depth of the probe, was used to determine water table depths. These data were validated through manual measurements of water table depths collected in the field during site visits. The mean absolute error between the values of water level estimated by the calibrated TDR output and those measured manually in the field was less than $1 \mathrm{~cm}$, and this error was considered negligible for the purposes of the investigation.
On April 2014, artificial rainfall was applied once at the FG site and twice at the HM site. In each site, a network of irrigation sprinklers was arranged in an area about $12 \mathrm{~m}$ long and $8 \mathrm{~m}$ large, located immediately upslope of the interceptor drain and including all the monitoring wells. At the HM site, irrigation water was applied below the trees to exclude interception by tree canopy.

In this site, a steady rainfall of $40 \mathrm{~mm} \mathrm{~h}^{-1}$ was applied for about $2.75 \mathrm{~h}$ on April 1. This irrigation was mainly made with the aim of increasing the soil moisture of the irrigated plot to a level comparable to that observed at the FG site. Two days after, a steady rainfall of $60 \mathrm{~mm} \mathrm{~h}^{-1}$ was applied for 2.7 hours at both the FG and HM sites.

\section{Estimation of the lateral saturated soil hydraulic conductivity}

The observed groundwater levels and the drained subsurface flow were used to estimate the lateral saturated soil hydraulic conductivity, $K_{s, l}\left[\mathrm{~L} \mathrm{~T}^{-1}\right]$, according to Childs (1971) and Brooks et al. (2004). In particular, Childs (1971) presented a solution to groundwater flow to a transverse ditch or tile line over a sloping impermeable bed. Brooks et al. (2004) applied the Childs (1971) solution to compute $K_{s, l}$ at an isolated sloping plot $35 \mathrm{~m}$ long and $18 \mathrm{~m}$ wide. Assuming that the groundwater flow lines are parallel to the bed, following the DupuitForchheimer approximation, flow of water per unit width of the drain, $q\left[\mathrm{~L}^{2} \mathrm{~T}^{-1}\right]$, can be modelled by means of the Darcy's law:

$q=-K_{s, l} T\left(\frac{d Z}{d s}\right)$

where $T[\mathrm{~L}]$ is the thickness of the saturated layer, measured perpendicular to the impermeable bed, $Z[\mathrm{~L}]$ is the water table elevation from an arbitrary datum, and $s[\mathrm{~L}]$ is the distance along the hillslope. In this investigation, $q, T$, and $d Z / d s$ were measured during field monitoring or determined using simple geometry. In this way, Eq. (1) can be solved directly to obtain a relation between $K_{s, l}$ and the water table depth below the soil surface.

\section{RESULTS \\ Natural rainfall}

Cumulative rainfall was $550 \mathrm{~mm}$ in 2014 and $528 \mathrm{~mm}$ in 2015 . For the analysis, rainfall events were considered distinct if they were separated by at least 6 hours without rain, and events with less than $3 \mathrm{~mm}$ in six hours were disregarded. About eighty events, ranging in depth from 3.2 to $91 \mathrm{~mm}$, occurred between January 2014 and December 2015. At the FG site, subsurface flow was observed during $80 \%$ of these events, mainly occurring during the autumn and spring periods. The maximum and the mean outflow volumes were about $3.6 \mathrm{~m}^{3}$ and $1.3 \mathrm{~m}^{3}$, respectively, and the maximum outflow rate was 11.7 $\mathrm{L} \mathrm{min}^{-1}$. At the HM site, drainage was less frequent than at the FG site and the collected water volumes were scarce. In particular, the drain intercepted subsurface flow for $40 \%$ of the rain events. The maximum and the mean collected water volumes were 0.3 and $0.05 \mathrm{~m}^{3}$, respectively, and the maximum outflow rate was $2 \mathrm{~L} \mathrm{~min}^{-1}$. Therefore, only few information about $K_{s, l}$ were obtained for the maquis soil. Considering the weak hydrological response of the HM site under natural rainfall, the hydraulic characterization of this site was only based on the artificial rainfall experiments. 


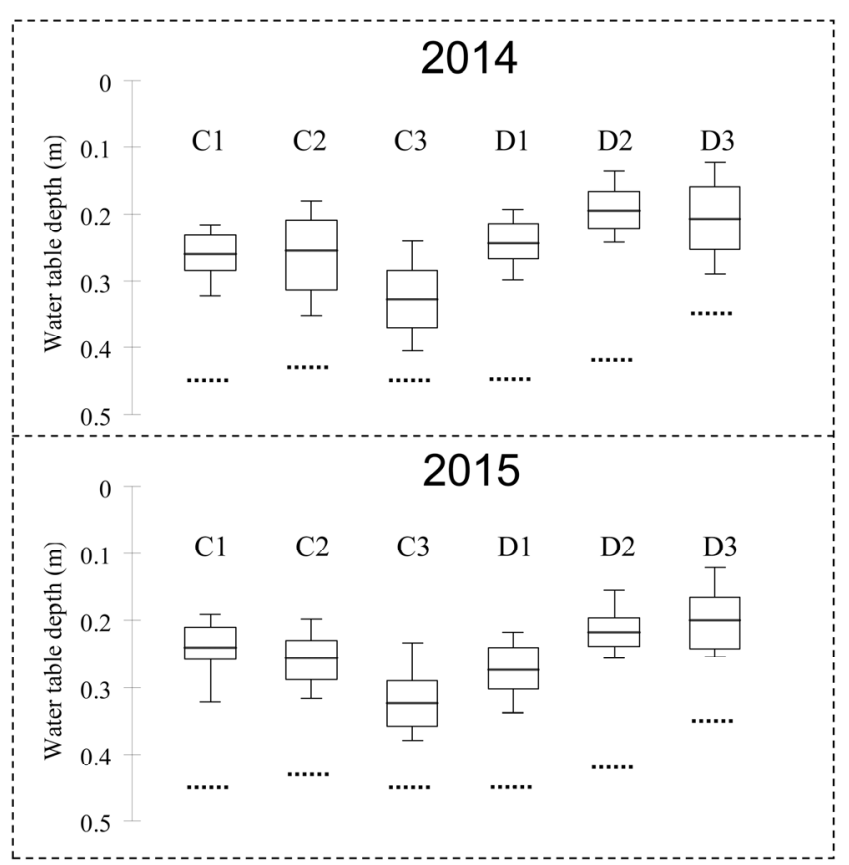

Fig. 2. Boxplots of the water table depth in each well at the FG site for the years 2014 and 2015. Only periods of natural rainfall are considered in the analysis. The boxes determine the $25^{\text {th }}$ and $75^{\text {th }}$ percentiles, the whiskers are the $10^{\text {th }}$ and $90^{\text {th }}$ percentiles, the horizontal lines within the boxes indicate the means. The dashed lines indicate the depth of the impeding layer as documented during well drilling.

At the FG site, a water table developed in autumn and spring only as a consequence of the greatest rainfall events. In winter, with high rainfall and low evapotranspiration, a water table steadily formed in the hillslope and, due to the high soil wetness, even small rainfall events caused piezometer responses. Figure 2 shows a boxplot of the observed water table depths at the FG site. On the contrary, the piezometer responses were almost absent at the HM site throughout the monitored period. For consistency of the analysis, only periods when all instruments were simultaneously functioning were considered. Lack of data was due to malfunctioning of some device or to water level fluctuations greater than those measurable by the TDR probes. Data from all instruments were simultaneously available for the $80 \%$ of the time during the period of occurrence of drain outflow.

The water table in the $\mathrm{C} 3$ well was the deepest on both years whereas the water levels in the D2 and D3 wells were the closest to the soil surface. The observed similarity between the two years of observation suggests that there was a temporal stability in the groundwater spatial dynamics in the hillslope. The piezometer responses were consistent between wells located at the same elevation in the hillslope. On both years, the lowest Spearman correlation coefficients, $\rho$, were detected with reference to the water levels in the C2 and D2 wells ( $\rho=0.81$ in 2014 and $\rho=0.92$ in 2015) whereas the highest $\rho$ values were obtained for the C3 and D3 wells ( $\rho=0.96$ and 0.95 , respectively).

Figure 3 shows a boxplot of the hydraulic gradients, $d Z / d s$, estimated from the water levels in the wells located 1 and $3 \mathrm{~m}$ far away the drain along the two established transects. The gradients used for $K_{s . l}$ calculation (Eq. 1) were computed as the arithmetic mean of the hydraulic gradients along the two transects near the drain. Only the wells near the drain were considered in order to have a more accurate estimate of the gradients

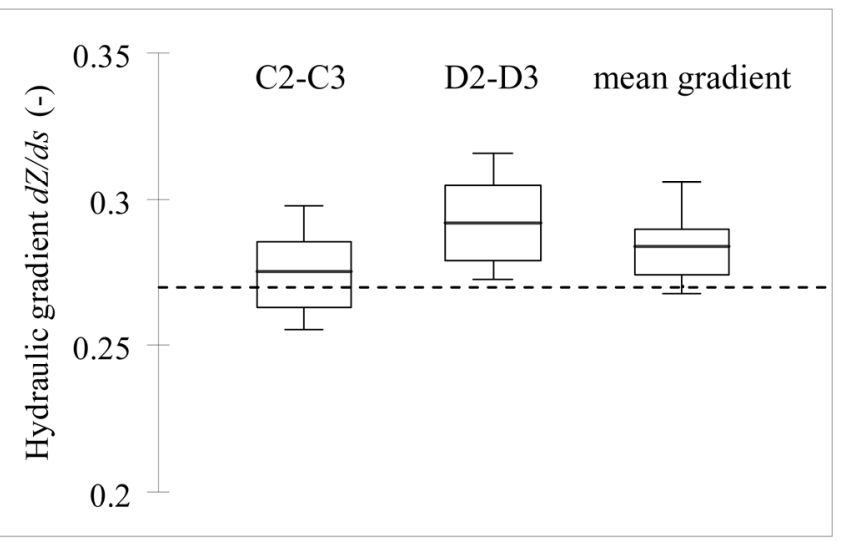

Fig. 3. Boxplot of the hydraulic gradient, $d Z / d s$, values measured near the drain at the FG site for the years 2014 and 2015. The statistical spread of mean hydraulic gradient used in Eq. (1) is also showed. The boxes determine the $25^{\text {th }}$ and $75^{\text {th }}$ percentiles, the whiskers are the $10^{\text {th }}$ and $90^{\text {th }}$ percentiles, the horizontal lines within the boxes indicate the means. The dashed line indicates the local topographic gradient.

that effectively drove the drain response. Figure 3 shows the statistical spread of the $d Z / d s$ values. Generally, the hydraulic gradients were close to the topographic gradient, and deviations from this latter did not exceed $5 \%$ in most cases.

The relationship between water table depth and outflow was investigated in detail by checking the hydrological response of the hillslope during a sequence of distinct rainfall events. Figure $4 \mathrm{~b}$ shows the response of the drain and the water levels in the three wells of transect $\mathrm{C}$ for the period from February 2 to February 5, 2014. Data from a single transect were considered for this analysis due to the detected consistence between well data for the two transects and also because similar results to those reported in Figure $4 \mathrm{~b}$ were obtained by either considering transect D or averaging the two transects (data not shown). Lateral subsurface flow was almost absent on February 2, when $5 \mathrm{~mm}$ of rainfall caused a large fluctuation of the water table close to the $\mathrm{C} 3$ well but levels in the $\mathrm{C} 1$ and $\mathrm{C} 2$ wells varied by only a few centimeters. Seven and $8 \mathrm{~mm}$ of rainfall fell on February 3 and 4, respectively. The water level in the C3 well fluctuated and peaked, with a behavior similar to that observed for the previous event. For the $\mathrm{C} 1$ and $\mathrm{C} 2$ wells, water levels closer to the soil surface were observed. Both amount and peak of the outflow showed a variation between events larger than the variation in fallen rain. Therefore, a rise in water level in the C3 well alone was not enough to collect significant subsurface runoff volumes. Instead, the water table rise close to the soil surface in the drained area was a necessary condition for generation of considerable subsurface flow. A possible physical interpretation of this finding is that higher water levels increased hydraulic connectivity of the soil pore system.

The time correspondence between water table level fluctuations and drain outflow response was also detected when peaks in both drain outflow and water table rise were well identifiable (Figure $4 b$ ). In general the increase of water table started simultaneously in all wells and the time when levels peaked also coincided among wells. The drain outflow dynamics closely followed the water table dynamics. In fact, outflow started to increase when water table began to respond, and the outflow and water table levels peaked at the same time.

To establish the best estimate of the saturated layer thickness, $T$, to be used in Eq. (1), an estimate of the water table depth, WTD, at a given elevation along the hillslope was obtained 


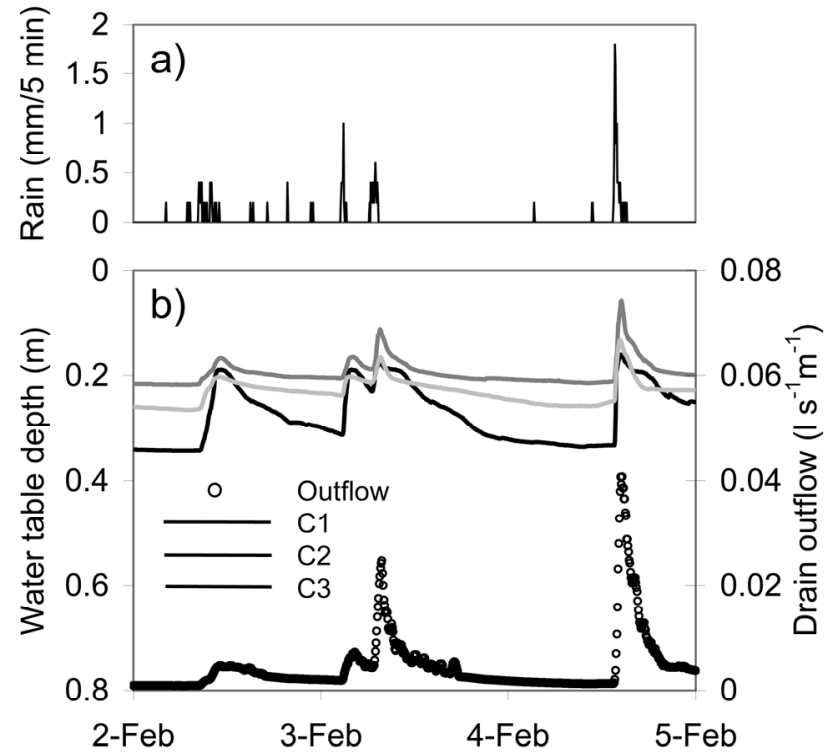

Fig. 4. a) Observed rainfall and b) observed drain outflow at the FG site and observed water table depths in the wells C1, C2 and C3 during the natural rainfall events occurring from 2 to 5 February 2014.

by averaging the two water level values and the correlation between $q$ and $W T D$ was checked. The lowest correlation between $q$ and WTD ( $\rho=0.86)$ was found for the 2014 data and the wells farther away from the drain (C1 and D1). The highest correlation was obtained by considering the closest wells to the drain $\left(W T D_{3}\right.$, i.e. the average of the $\mathrm{C} 3$ and $\mathrm{D} 3$ well levels), since $\rho$ was close to 0.93 on both years. Therefore, $W T D_{3}$ was used for the calculation of $T$ in Eq. (1).

Taking into account the similarity of the relationships between $q$ and $W T D_{3}$ for the two monitored years, a single $q\left(W T D_{3}\right)$ relationship was developed by considering the $q\left(W T D_{3}\right)$ data of both years. This relationship was clearly nonlinear (Figure 5). Above the depth of about $0.17 \mathrm{~m}$ (small thickness of the saturated layer), $q$ varied by $2 \times 10^{-4} \mathrm{~L} \mathrm{~s}^{-1} \mathrm{~m}^{-1}$ per centimeter of WTD fluctuation. Below this depth (thicker saturated layer), $q$ variation per unit change in water table depth was 25 times greater. This result suggested that $K_{s, l}$ greatly increased in the upper soil layer.

The highest estimated $K_{s, l}$ values were close to $3000 \mathrm{~mm} \mathrm{~h}^{-1}$ for a $W T D$ of about $0.1 \mathrm{~m}$ (Figure $6 \mathrm{a}$ ). Similar results (i.e., $K_{s, l}$ $=3600 \mathrm{~mm} \mathrm{~h}^{-1}$ ) were obtained by Montgomery and Dietrich (1995) in a soil presenting the evidence of macropore flow. The rate of change of $K_{s, l}$ with $W T D$ increased by more than one order of magnitude in the passage from small (i.e., $W T D \geq 0.17$ $\mathrm{m})$ to large saturated soil layers. Figure $6 \mathrm{~b}$ shows that the $K_{s, l}$ data were more prone to uncertainty (higher coefficients of variation, $C V$ ) for small water table levels (high $W T D$ values). This result was a consequence of the relatively poor correlation between $q$ and $W T D$ for the high $W T D$ values (Figure 5). A low correlation between the trench outflow and the water table depth for low subsurface flow regimes was also observed in other experimental hillslopes (Anderson et al., 2009; Uchida et al., 2004). The observed trend of $K_{s, l}$ as a function of $W T D_{3}$ was satisfactorily modelled by an exponential function (Figure 6a). This model is in agreement with the assumption of many hydrological models, such as TOPMODEL (Ambroise et al., 1996), that the soil transmissivity exponentially increases with the thickness of the saturated soil layer.

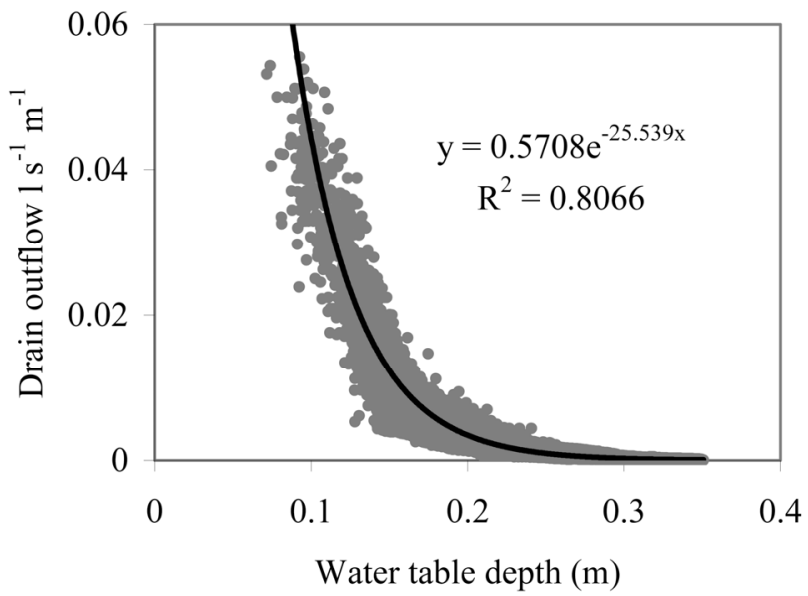

Fig. 5. Water flow per unit with of drain, $q$, vs. water table depth, $W T D_{3}$, values measured in the C3 and D3 wells of FG site for the natural rainfalls occurring in 2014-2015 years. The fitted exponential curve is also showed.

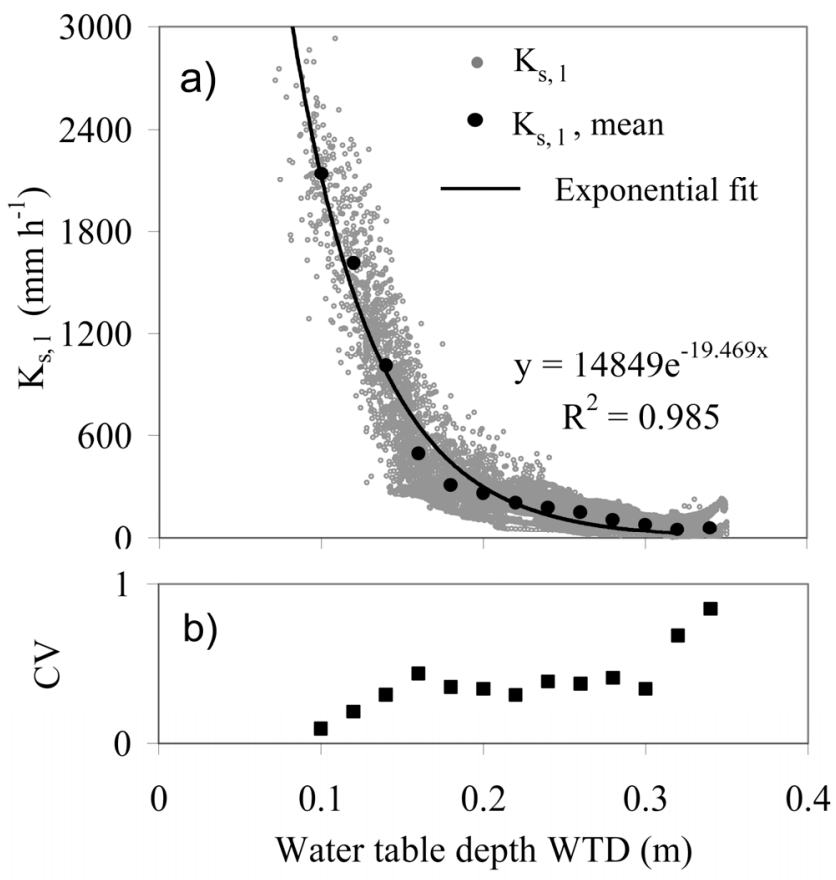

Fig. 6. a) Lateral saturated hydraulic conductivity, $K_{s, l}$, vs. water table depth values, $W T D_{3}$, for the natural rainfall occurring in 2014-2015 years. Average values of $K_{s, l}$ computed for selected water table depths are shown, together with the fitted exponential curve. b) Coefficients of variation $(\mathrm{CV})$ of $K_{s, l}$ for selected water table depths.

\section{Sprinkling experiment}

At the HM site, the first sprinkling experiment (rainfall intensity $=40 \mathrm{~mm} \mathrm{~h}^{-1}$ ) was carried out on an initially dry soil. The drain took about one hour to respond to the rainfall input. The outflow increased throughout the duration of the experiment, until $q=0.085 \mathrm{~L} \mathrm{~s}^{-1} \mathrm{~m}^{-1}$ was reached at the end of the experiment (Figure 7). The total collected water volume was $1.6 \mathrm{~m}^{3}$ and the runoff coefficient was 0.5 . Surface runoff did not occur during the experiment. 


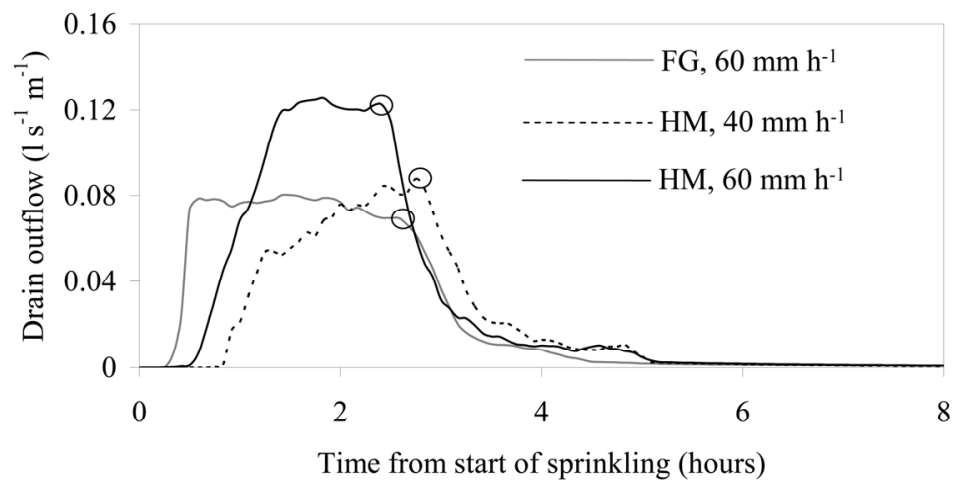

Fig. 7. Time series of the drain outflow observed during the sprinkling experiments in the FG and HM sites; circles indicate the end of water supply.

The second, more intense (rainfall intensity $=60 \mathrm{~mm} \mathrm{~h}^{-1}$ ) sprinkling experiment was carried out while the drain was slowly leaking. The drain responded about 30 minutes after irrigation started. Subsurface flow increased for an hour up to a steady rate of about $0.12 \mathrm{~L} \mathrm{~s}^{-1} \mathrm{~m}^{-1}$, which did not vary during the subsequent hour. The collected subsurface water volume was $2.25 \mathrm{~m}^{3}$, which represented about $51 \%$ of the total supplied water volume. Surface runoff generated during this experiment, and its water volume was about $8 \%$ of the supplied water volume.

The two sprinkling experiments at the HM site yielded similar $q\left(W T D_{3}\right)$ relationships (Figure $8 \mathrm{a}$ ). A complete saturation of the soil layer was never achieved, being $0.08 \mathrm{~m}$ the minimum reached water table depth. For a water table depth greater than about $0.25 \mathrm{~m}$ the drain response was almost absent while above this depth the outflow was highly responsive to changes in water table level. The $K_{s, l}\left(W T D_{3}\right)$ data points, fitted with an exponential function (Figure 8b), closely resembled the $q\left(W T D_{3}\right)$ relationship (Figure 8a). During the steady outflow phase, a mean $K_{s, l}$ value of $3750 \mathrm{~mm} \mathrm{~h}^{-1}$ was computed for $W T D=0.1 \mathrm{~m}$.

At the FG site, the sprinkling experiment (rainfall intensity = $60 \mathrm{~mm} \mathrm{~h}^{-1}$ ) was carried out on initially wet soil and while the tile line was slowly draining. The drain took about 20 minutes to respond to the rainfall input. The outflow increased for 15 minutes, until it reached a steady rate of about $0.08 \mathrm{~L} \mathrm{~s}^{-1} \mathrm{~m}^{-1}$ (Figure 7). The maximum surface runoff rate was $0.08 \mathrm{~L} \mathrm{~s}^{-1} \mathrm{~m}^{-1}$. The total subsurface flow and surface runoff volumes were of about $2 \mathrm{~m}^{3}$, representing the $83 \%$ of the supplied water volume.

The $K_{s, l}$ value estimated during the steady outflow phase was $3200 \mathrm{~mm} \mathrm{~h}^{-1}$ and in this case the soil was almost completely saturated (Figure 8d). For a given water table depth, less outflow was measured at the FG site than the HM site one (Figure $8 \mathrm{c})$. An abrupt change of the outflow rate vs. water table level relationship was observed for WTD of about $0.20 \mathrm{~m}$.

\section{DISCUSSION}

Two years of continuous monitoring highlighted that the land use had a primary role in controlling the hydrological response to rainfall of the sampled hillslope. At the FG site water table and lateral subsurface flow developed and persisted for long periods throughout the rainy seasons. At this site, even small water inputs were enough to increase lateral saturated subsurface flow when the soil was wet and the water table was close to the soil surface. A similar finding was reported by
McDaniel et al. (2008). At the adjacent HM site, the groundwater response was weak, and both the peaks and the volumes of the generated outflow were very low throughout the study period. Weaker piezometer responses to rainfall in forested than grassed hillslopes have also been signalled by Germer et al. (2010) and Rockefeller et al. (2004). This result was also in line with other investigations showing an increase in water yield in catchments where forest was partially cleared (Brown et al. 2005; Molina et al. 2012; Sahin and Hall, 1996). At the HM site Pirastru et al. (2014) observed that $30 \%$ of the annual gross rainfall was intercepted by the canopy. This result was in line with the canopy interception values observed by other Authors under shrubs and trees in other natural semi-arid Mediterranean environments (Gallart et al. 2002; Llorenz and Domingo, 2007). The canopy interception and the water retained by the thick litter on the soil surface create additional water storage that needs to be replenished by the rainfall. This may contribute to delay the beginning of the perched water table formation, to a point that soil saturation does not occur in years with low rainfall. At the HM site, we cannot exclude the possibility that the high canopy interception was the main cause of the almost absent saturated subsurface flow and water table rises during the natural rainfall events, also considering that annual rainfall was slightly below the average on both 2014 and 2015 . For this site, a longer period of observation is probably necessary to adequately characterize the lateral subsurface flow of the soil under natural rainfall conditions. Wilcox et al. (1997) also stated that hydrological monitoring in forested semi-arid environments normally requires long periods of observation because runoff-producing events are rare and of short duration, and they only occur under infrequent conditions, such as high rainfall and high antecedent soil moisture conditions.

In both the FG and HM sites, the relationship between the lateral saturated subsurface flow and the water table level was highly non-linear, and abruptly changed for small WTDs. Abrupt changes in the relationships between subsurface storage indicators (e.g., soil moisture or groundwater levels) and the subsurface flow have been reported for different hydrological processes and spatial scales of observation (Latron and Gallart, 2008; Penna et al., 2011; Peters et al., 2003). This investigation showed that the change in the $q(W T D)$ relationship was linked to $K_{s, l}$, which increased sharply when the water table level was higher than $0.17-0.2 \mathrm{~m}$ at the FG site and about $0.25 \mathrm{~m}$ at the HM site. This behaviour plausibly reflected the increased density of macropores near the surface, due to roots and micro-fauna activity. Moreover, the increase of the water levels increased 

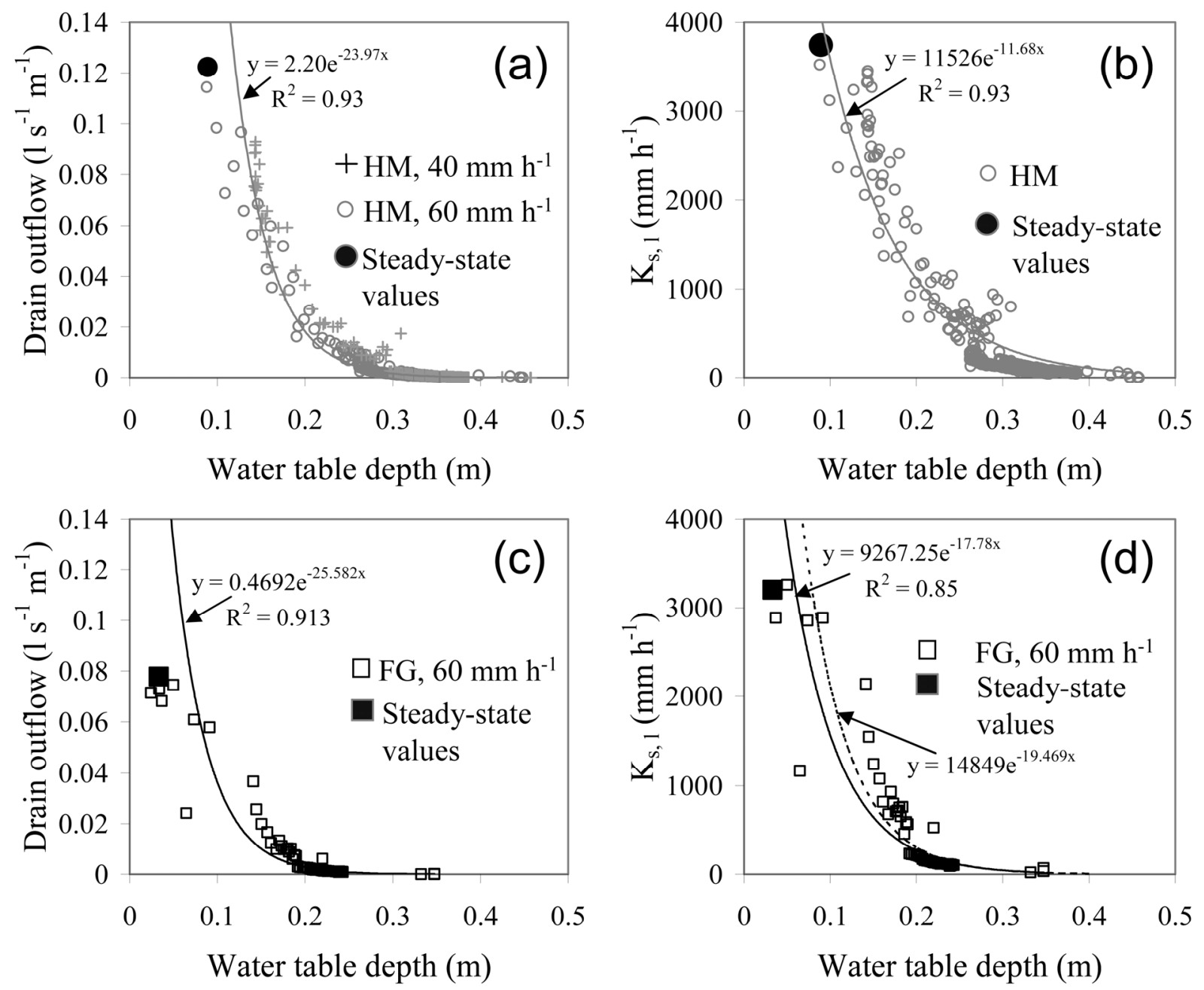

Fig. 8. a) Water flow per unit width of drain, $q$, vs. water table depth, $W T D_{3}$, values measured in the HM site during the transient and steady-state phases of the sprinkling experiments; b) lateral saturated hydraulic conductivity, $K_{s, l}$, vs. $W T D_{3}$ estimated for the sprinkling experiments in the HM site; c) $q$ vs. $W T D_{3}$ values measured in the FG site during the transient and steady- state phases of the sprinkling experiment; d) $K_{s, l}$ vs. $W T D_{3}$ estimated for the sprinkling experiment in the FG site. The continuous lines are the exponential functions fitted to the $q\left(W T D_{3}\right)$ and $K_{s, l}\left(W T D_{3}\right)$ data estimated for the sprinkling experiments at the HM and FG sites. The dashed line in the Figure $8 \mathrm{~d}$ is the exponential function fitted to the $K_{s, l}\left(W T D_{3}\right)$ data determined for the natural rainfall periods at the FG site, already shown in the Figure 6a.

the possibility of a spatial connection between isolated patches of permeable soil or macropore network, thus increasing the lateral hydraulic connectivity of the soil pore system as a whole. The increase of $K_{s, l}$ near the surface was most apparent at the HM site compared to the FG site (Figures $8 \mathrm{~b}$ and $8 \mathrm{~d}$ ). Plausibly, this result was expressive of the more developed and effective macroporosity in the soil under the maquis compared to the grassed soil, in line with other studies comparing forest and cleared land soils (Alaoui et al., 2011). In situ observations of the distribution of tree and shrub roots in the maquis indicated that fine roots were abundant close to the surface and that many coarse roots developed more in depth, spreading both laterally and vertically. This root structure contributed to increase the hydraulic conductivity of the maquis to a depth greater than that observed at the grassed site.

At the FG site, a minimum water table depth (largest saturated layer) of $0.1 \mathrm{~m}$ was observed during the natural rainfall periods, and the corresponding $K_{s, l}$ value was of $3000 \mathrm{~mm} \mathrm{~h}^{-1}$. During the steady outflow phase of the sprinkling experiment, the water table was on average $0.03 \mathrm{~m}$ below the soil surface and a $K_{s, l}$ value of $3200 \mathrm{~mm} \mathrm{~h}^{-1}$ was estimated. In Figure 8d, this last $K_{s, l}$ value appears shifted to the left as compared with the exponential $K_{s, l}(W T D)$ relationship obtained for the natural rainfall periods. Therefore, the results of the sprinkling experiment suggested that, for water table depths smaller than those observed during the natural rainfall periods, there was a stabilization of the $K_{s, l}$ values, thus resulting in a flattening of the $K_{s, l}(W T D)$ relationship close to the soil surface. An analysis of the relationships between $K_{s, l}$ and the subsurface flow rates observed with both the natural and artificial rainfall at the FG site (Figure 9a) better clarified this finding. The increases of $K_{s, l}$ with $q$ was less than proportional and a power function with an exponent of 0.82 well described this behaviour. In the range of the outflow rates observed during the natural rainfall, there was a good agreement between the $K_{s, l}(q)$ data points obtained for these periods and those corresponding to the sprinkling experiment. However, beyond this range, the highest $K_{s, l}(q)$ values that were estimated with the sprinkling experiment exhibited a less steep pattern, indicating that the increase of $K_{s . l}$ was slower when the water table was closer to the soil surface. A similar flattening of the $K_{s, l}(q)$ relationship was observed by Montgomery and Dietrich (1995), who found that $K_{s, l}$ increased sharply 

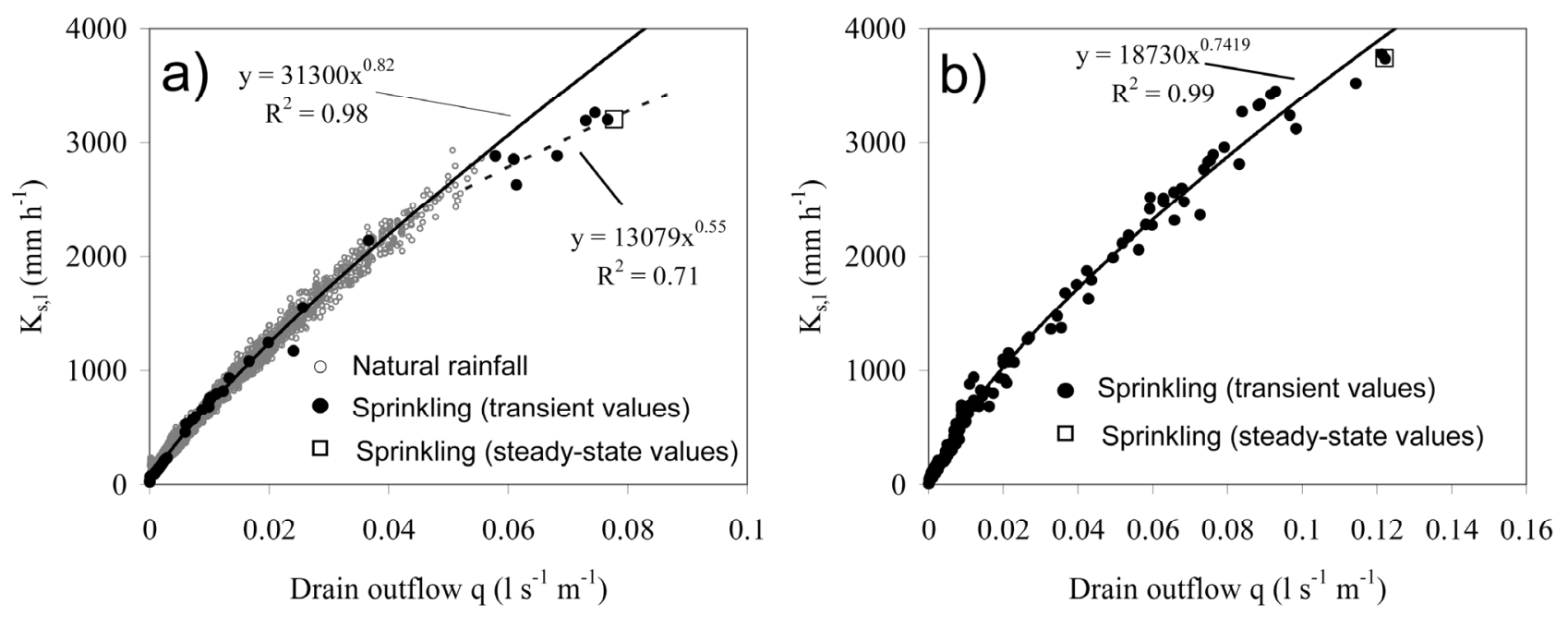

Fig. 9. Lateral saturated hydraulic conductivity, $K_{s, l}$, vs. water flow per unit with of drain, $q$, for (a) the natural rainfall events of years 2014-2015 and the sprinkling experiment in the FG site, and (b) the sprinkling experiments in the HM site.

with $q$ for low discharge values but it was relatively stable at the highest observed discharges. These authors explained the observed behaviour by the progressive filling of macropores that became full of water at the highest discharges. In agreement with Montgomery and Dietrich (1995), Figure 9a suggests that the capacity of the soil pore system to transmit flow downslope reached the maximum during the sprinkling experiment. Conversely, the full potential of the system was not reached during the natural rainfall periods.

At the HM site, the saturated conductivity estimated during the steady outflow phase of the sprinkling experiments was in line with the exponential $K_{s, l}(W T D)$ relationship obtained by considering the transient phases of the same experiments (Figure $8 \mathrm{~b})$. Figure $9 \mathrm{~b}$ also suggests that, despite the high applied rain intensity and the intense drain response, the full potential of the maquis soil in transporting the lateral subsurface flow was only partially explored. For this soil, it is reasonable not to exclude the possibility that $K_{s, l}$ continues to increase up to the soil surface, as observed for example by Brooks et al. (2004).

Brooks et al. (2004) highlighted the need to introduce simplifications in the experimental methodology for estimating $K_{s, l}$ at the hillslope scale, in order to make the method more suitable for routine determinations. A possible simplification could be using the topographic gradient instead of the hydraulic gradient $d Z / d s$ in Eq. (1). This suggestion stems from the observation that the water table was almost parallel to the surface for most part of the time (Figure 3). Figure 10 shows that, with the topographic gradient instead of $d Z / d s$ in Eq. (1), the absolute errors in $K_{s, l}$ did not exceed $20 \%$ and they were smaller than $10 \%$ for $K_{s, l}>500 \mathrm{~mm} \mathrm{~h}^{-1}$.

In this investigation, a $2.5 \mathrm{~m}$ long drain was used to intercept flow from a non-isolated portion of the hillslope notwithstanding that both sampled sites (HM and FG) were appreciably wider (Figure 1). Therefore, the sampling scheme was different from that by Brooks et al. (2004), since these authors used a long drain $(18 \mathrm{~m})$ to collect all subsurface flow generated in an isolated hillslope plot. Assuming that flow was perfectly perpendicular to the drain could not be totally exact, since some lateral convergence or divergence of the saturated flow pathways cannot be excluded. However, the results of this investigation were consistent with those by Brooks et al. (2004). In particular, there were signs that macropore contribution to the hydrological response of the hillslope was adequately captured

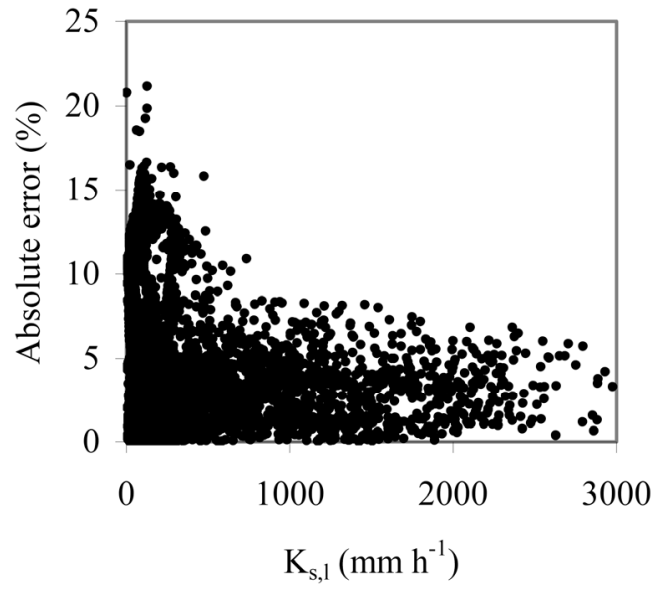

Fig. 10. Absolute percentage errors introduced in the estimate of the lateral saturated hydraulic conductivity, $K_{s, l}$, by using the topographic gradient in lieu of the total hydraulic gradient in Eq.(1).

since rapid flow was found to be particularly noticeable when the water table was close to the soil surface. Moreover, the experimental setup used at the HM and FG sites is simpler to replicate in other hillslopes than the one involving hydraulic isolation of the plot and interception of all subsurface flow. Therefore, the experimental methodology used at the Baratz Lake catchment potentially appears a good method to develop other databases in different environments, which is expected to improve our general knowledge of subsurface flow processes. Evidently, further investigations are advisable to test the assumption of perpendicular flow used in this approach, also establishing what happens with drains differing in length.

\section{CONCLUSIONS}

The experimental investigation was carried out to characterize the lateral saturated subsurface flow processes in a hillslope with two plots covered with Mediterranean maquis and grass, respectively. The spatially variable water table levels and the lateral saturated subsurface flows drained at the basis of the hillslope were used for determining relationships between the large-scale lateral saturated soil hydraulic conductivity, $K_{s, l}$, and 
the thickness of the water table above the impeding layer. The $K_{s, l}$ sharply increased when the water table level was close to the soil surface, where macropores were mostly present. Probably, high water table levels were necessary in the drained area to make large-scale hydraulic connection of the macropore system effective. Further experimental work is need to confirm the role of the macropores in controlling the $K_{s, l}$ at the studied hillslope. For example, near point determinations of the vertical profile of hydraulic conductivity should be carried out to increase our confidence that a depth-dependent macroporosity was responsible of the detected hydrological response of the hillslope.

In situ experiments for large scale $K_{s, l}$ estimation, such as that illustrated in this paper, are expensive and time consuming. For catchment-scale hydrological studies near-point $K_{s, l}$ determinations remain the only feasible way to obtain spatially distributed $K_{s, l}$ data. In the studied hillslope it would be interesting to carry out a distributed point sampling of the hydraulic conductivity and compare the results with the large scale $K_{s, l}$. In fact, using $K_{s, l}$ resulting from this study as a benchmark, may increase knowledge on the way a distributed point sampling should be planned to obtain useful information for interpreting and simulating subsurface hydrological processes at the hillslope scale.

\section{REFERENCES}

Alaoui, A., Caduff, U., Gerke, H.H., Weingartner, R., 2011. A preferential flow effects on infiltration and runoff in grassland and forest soils. Vadose Zone Journal, 10, 1, 367377.

Ambroise, B., Beven, K., Freer, J., 1996. Toward a generalization of the TOPMODEL concepts: Topographic indices of hydrological similarity. Water Resources Research, 32, 7, 2135-2145.

Anderson, A.E., Weiler, M., Alila, Y., Hudson, R.O., 2009. Subsurface flow velocities in a hillslope with lateral preferential flow. Water Resources Research, 45, 11.

Bathke, G.R., Cassel, D.K.,1991. Anisotropic variation of profile characteristics and saturated hydraulic conductivity in an Ultisol landscape. Soil Science Society of America Journal, 55, 2, 333-339.

Baxter, C., Hauer, F.R., Woessner, W.W., 2003. Measuring groundwater-stream water exchange: new techniques for installing minipiezometers and estimating hydraulic conductivity. Transactions of the American Fisheries Society, 132, 3, 493-502.

Beckwith, C.W., Baird, A.J., Heathwaite, A.L., 2003. Anisotropy and depth-related heterogeneity of hydraulic conductivity in a bog peat. II: modelling the effects on groundwater flow. Hydrological Processes, 17, 1, 103-113.

Beven, K., Germann, P., 2013. Macropores and water flow in soils revisited. Water Resources Research, 49, 6, 30713092.

Blain, C.A., Milly, P.C.D., 1991. Development and application of a hillslope hydrologic model. Adv. Water Resour., 14, 4, $168-174$

Blanco-Canqui, H., Gantzer, C.J., Anderson, S.H., Alberts, E.E., Ghidey, F., 2002. Saturated hydraulic conductivity and its impact on simulated runoff for claypan soils. Soil Science Society of America Journal, 66, 5, 1596-1602.

Bouma, J., Dekker, L.W., 1981. A method for measuring the vertical and horizontal $K_{\text {sat }}$ of clay soils with macropores. Soil Science Society of America Journal, 45, 3, 662-663.
Brooks, E.S., Boll, J., McDaniel, P.A., 2004. A hillslope-scale experiment to measure lateral saturated hydraulic conductivity. Water Resources Research, 40, 4.

Brown, A. E., Zhang, L., McMahon, T. A., Western, A. W., Vertessy, R. A., 2005. A review of paired catchment studies for determining changes in water yield resulting from alterations in vegetation. Journal of Hydrology, 310, 1, 28-61.

Castellini, M., Iovino, M., Pirastru, M., Niedda, M., Bagarello, V., 2016. Use of BEST procedure to assess soil physical quality in the Baratz Lake catchment (Sardinia, Italy). Soil Science Society America Journal, 80, 742-755.

Chappell, N.A., 2010. Soil pipe distribution and hydrological functioning within the humid tropics: a synthesis. Hydrological Processes, 24, 12, 1567-1581.

Chappell, N.A., Franks, S.W., Larenus, J., 1998. Multi-scale permeability estimation for a tropical catchment. Hydrological Processes, 12, 1507-1523.

Chappell, N.A., Lancaster, J.W., 2007. Comparison of methodological uncertainties within permeability measurements. Hydrological Processes, 21, 18, 2504-2514.

Childs, E.C., 1971. Drainage of groundwater resting on a sloping bed. Water Resources Research, 7, 5, 1256-1263.

Dabney, S.M., Selim, H.M., 1987. Anisotropy of a fragipan soil: vertical vs. horizontal hydraulic conductivity. Soil Science Society of America Journal, 51, 1, 3-6.

Dusek, J., Vogel, T., 2016. Hillslope-storage and rainfallamount thresholds as controls of preferential stormflow. Journal of Hydrology, 534, 590-605.

Dusek, J., Vogel, T., Dohnal, M., Gerke, H.H., 2012. Combining dual-continuum approach with diffusion wave model to include a preferential flow component in hillslope scale modeling of shallow subsurface runoff. Advances in Water Resources, 44, 113-125.

Gallart, F., Llorens, P., Latron, J., Regüés, D., 2002. Hydrological processes and their seasonal controls in a small Mediterranean mountain catchment in the Pyrenees. Hydrology and Earth System Sciences Discussions, 6, 3, 527-537.

Germer, S., Neill, C., Krusche, A.V., Elsenbeer, H., 2010. Influence of land-use change on near-surface hydrological processes: undisturbed forest to pasture. Journal of Hydrology, 380, 3, 473-480.

Giadrossich, F., Niedda, M., Cohen, D., Pirastru, M., 2015. Evaporation in a Mediterranean environment by energy budget and Penman methods, Lake Baratz, Sardinia, Italy. Hydrology and Earth System Sciences, 19, 5, 2451-2468.

Grayson, R.B., Moore, I.D., McMahon, T.A., 1992. Physically based hydrologic modeling: 2. Is the concept realistic? Water Resources Research, 28, 10, 2659-2666.

Hilberts, A.G.J., Troch, P.A., Paniconi, C., 2005. Storagedependent drainable porosity for complex hillslopes. Water Resources Research, 41, 6.

Jost, G., Schume, H., Hager, H., Markart, G., Kohl, B., 2012. A hillslope scale comparison of tree species influence on soil moisture dynamics and runoff processes during intense rainfall. Journal of Hydrology, 420, 112-124.

Latron, J., Gallart, F., 2008. Runoff generation processes in a small Mediterranean research catchment (Vallcebre, Eastern Pyrenees). Journal of Hydrology, 358, 3, 206-220.

Llorens, P., Domingo, F., 2007. Rainfall partitioning by vegetation under Mediterranean conditions. A review of studies in Europe. Journal of Hydrology, 335, 1, 37-54.

Maneta, M., Schnabel, S., Jetten, V., 2008. Continuous spatially distributed simulation of surface and subsurface hydrological processes in a small semiarid catchment. Hydrological Processes, 22, 13, 2196-2214. 
Matonse, A.H., Kroll, C.N., 2013. Applying hillslope-storage models to improve low flow estimates with limited streamflow data at a watershed scale. Journal of Hydrology, 494, 20-31.

McDaniel, P.A., Regan, M.P., Brooks, E., Boll, J., Barndt, S., Falen, A., Young, S.K., Hammel, J.E., 2008. Linking fragipans, perched water tables, and catchment-scale hydrological processes. Catena, 73, 2, 166-173.

Molina, A., Vanacker, V., Balthazar, V., Mora, D., Govers, G., 2012. Complex land cover change, water and sediment yield in a degraded Andean environment. Journal of Hydrology, 472, 25-35.

Montgomery, D.R., Dietrich, W.E., 1995. Hydrologic processes in a low-gradient source area. Water Resources Research, $31,1,1-10$.

Morgan, R.P.C., Duzant, J.H., 2008. Modified MMF (MorganMorgan-Finney) model for evaluating effects of crops and vegetation cover on soil erosion. Earth Surface Processes and Landforms, 33, 1, 90-106.

Newman, B.D., Campbell, A.R., Wilcox, B.P., 1998. Lateral subsurface flow pathways in a semiarid ponderosa pine hillslope. Water Resources Research, 34, 12, 3485-3496.

Niedda, M., Pirastru, M., 2013. Hydrological processes of a closed catchment-lake system in a semi-arid Mediterranean environment. Hydrological Processes, 27, 25, 3617-3626.

Niedda, M., Pirastru, M., 2015. Field investigation and modelling of coupled stream discharge and shallow water-table dynamics in a small Mediterranean catchment (Sardinia). Hydrological Processes, 28, 21, 5423-5435. DOI: 10.1002/hyp.10016

Niedda, M., Pirastru, M., Castellini, M., Giadrossich, F., 2014. Simulating the hydrological response of a closed catchmentlake system to recent climate and land-use changes in semiarid Mediterranean environment. Journal of Hydrology, 517, 732-745.

Penna, D., Tromp-van Meerveld, H.J., Gobbi, A., Borga, M., Dalla Fontana, G., 2011. The influence of soil moisture on threshold runoff generation processes in an alpine headwater catchment. Hydrology and Earth System Sciences, 15, 3, 689-702.

Peters, N.E., Freer, J., Aulenbach, B.T., 2003. Hydrological dynamics of the Panola Mountain research watershed, Georgia. Ground Water, 41, 7, 973-988.

Pirastru, M., Niedda, M., 2013. Evaluation of the soil water balance in an alluvial flood plain with a shallow groundwater table. Hydrological Sciences Journal, 58, 4, 898-911.
Pirastru, M., Niedda, M., Castellini, M., 2014. Effects of maquis clearing on the properties of the soil and on the nearsurface hydrological processes in a semi-arid Mediterranean environment. Journal of Agricultural Engineering, 45, 4, 176-187.

Reynolds, W.D., 2010. Measuring soil hydraulic properties using a cased borehole permeameter: steady flow analyses. Vadose Zone Journal, 9, 3, 637-652.

Reynolds, W.D., 2011. Measuring soil hydraulic properties using a cased borehole permeameter: falling-head analysis. Vadose Zone Journal, 10, 3, 999-1015.

Rockefeller, S.L., McDaniel, P.A., Falen, A.L., 2004. Perched water table responses to forest clearing in northern Idaho. Soil Science Society of America Journal, 68, 168-174.

Sahin, V., Hall, M.J., 1996. The effects of afforestation and deforestation on water yields. Journal of Hydrology, 178, 1, 293-309.

Sherlock, M.D., Chappell, N.A., McDonnell, J.J., 2000. Effects of experimental uncertainty on the calculation of hillslope flow paths. Hydrological Processes, 14, 2457-2471.

Uchida, T., Asano, Y., Mizuyama, T., McDonnell, J.J., 2004. Role of upslope soil pore pressure on lateral subsurface storm flow dynamics. Water Resources Research, 40, 12.

Van Schaik, N.L.M.B., Schnabel, S., Jetten, V.G., 2008. The influence of preferential flow on hillslope hydrology in a semi-arid watershed (in the Spanish Dehesas). Hydrological Processes, 22, 18, 3844-3855.

Van Schaik, N.L.M.B., Bronstert, A., Jong, S.M., Jetten, V.G., Dam, J.C., Ritsema, C.J., Schnabel, S., 2014. Process-based modelling of a headwater catchment in a semi-arid area: the influence of macropore flow. Hydrological Processes, 28, 24, 5805-5816.

Weiler, M., McDonnell, J.J., Tromp-van Meerveld, H.J., Uchida, T., 2005. Subsurface stormflow. In: Anderson, M.G., McDonnell, J.J. (Eds.): Encyclopedia of Hydrological Sciences, vol. 3. Wiley, Chichester, pp. 1719-1732.

Wilcox, B.P., Newman, B.D., Brandes, D., Davenport, D.W., Reid, K., 1997. Runoff from a semiarid ponderosa pine hillslope in New Mexico. Water Resources Research, 33, 10, 2301-2314.

Received 9 August 2016 Accepted 25 November 2016 